\title{
Opioid Hedonic Hotspot in Nucleus Accumbens Shell: Mu, Delta, and Kappa Maps for Enhancement of Sweetness "Liking" and "Wanting"
}

\author{
Daniel C. Castro and Kent C. Berridge \\ Department of Psychology, University of Michigan, Ann Arbor, Michigan 48109
}

\begin{abstract}
A specialized cubic-millimeter hotspot in the rostrodorsal quadrant of medial shell in nucleus accumbens (NAc) of rats may mediate opioid enhancement of gustatory hedonic impact or "liking". Here, we selectively stimulated the three major subtypes of opioid receptors via agonist microinjections [mu (DAMGO), delta (DPDPE), or kappa (U50488H)] and constructed anatomical maps for functional localizations of consequent changes in hedonic "liking" (assessed by affective orofacial reactions to sucrose taste) versus "wanting" (assessed by changes in food intake). Results indicated that the NAc rostrodorsal quadrant contains a shared opioid hedonic hotspot that similarly mediates enhancements of sucrose "liking" for mu, delta, and kappa stimulations. Within the rostrodorsal hotspot boundaries each type of stimulation generated at least a doubling or higher enhancement of hedonic reactions, with comparable intensities for all three types of opioid stimulation. By contrast, a negative hedonic coldspot was mapped in the caudal half of medial shell, where all three types of opioid stimulation suppressed "liking" reactions to approximately one-half normal levels. Different anatomical patterns were produced for stimulation of food "wanting", reflected in food intake. Altogether, these results indicate that the rostrodorsal hotspot in medial shell is unique for generating opioid-induced hedonic enhancement, and add delta and kappa signals to mu as hedonic generators within the hotspot. Also, the identification of a separable NAc caudal coldspot for hedonic suppression, and separate NAc opioid mechanisms for controlling food "liking" versus "wanting" further highlights NAc anatomical heterogeneity and localizations of function within subregions of medial shell.
\end{abstract}

Key words: nucleus accumbens; opioid

\section{Introduction}

The medial shell of nucleus accumbens (NAc) contributes to the hedonic impact of sensory pleasures (e.g., "liking" reactions to sweetness), as well as incentive motivation to consume foods, drugs, and other rewards (e.g., "wanting"; Zhang et al., 2003; Grueter et al., 2012; Michaelides et al., 2013; Resendez et al., 2013). Disorders, such as drug addiction, binge eating, or depression, may involve mesocorticolimbic dysfunction of "liking" or "wanting" processes (Koob, 2000; Ito et al., 2004; Nathan and Bullmore, 2009; Berridge et al., 2010; Berner et al., 2011).

An anatomically localized "hedonic hotspot" has been found within the rostrodorsal quadrant of NAc medial shell: an approximately cubic-millimeter sized subregion where mu opioid stimulation via microinjection of DAMGO can double the hedonic impact of sweet tastes (Peciña and Berridge, 2005; Smith and

Received Oct. 18, 2013; revised Feb. 5, 2014; accepted Feb. 13, 2014.

Author contributions: D.C.C. and K.C.B. designed research; D.C.C. performed research; D.C.C. and K.C.B. analyzed data; D.C.C. and K.C.B. wrote the paper.

This work was supported by National Institutes of Health Grants MH63649 and DA015188 to K.C.B., and D.C.C. was supported by a NIH Training Grant DC00011. We thank Aaron Garcia and Cristina Munoz for assistance with immunohistochemistry.

The authors declare no competing financial interests.

Correspondence should be addressed to Daniel Castro, Department of Psychology, University of Michigan, 530 Church Street, Ann Arbor, MI 48109. E-mail: castrod@umich.edu.

DOI:10.1523/JNEUROSCI.4458-13.2014

Copyright $\odot 2014$ the authors $\quad 0270-6474 / 14 / 344239-12 \$ 15.00 / 0$
Berridge, 2005, 2007; Smith et al., 2011). By contrast, the same $\mu$-opioid stimulation in other subregions of medial shell fails to enhance "liking" reactions to sucrose (Peciña and Berridge, 2005). As part of a larger functional circuit, the NAc hotspot interacts with a second anatomical hotspot in the ventral pallidum to amplify "liking" reactions to sweetness (Smith and Berridge, 2007; Smith et al., 2011).

Separable from hedonic impact, $\mu$-opioid stimulation also increases the motivation to eat ("wanting") both in the shell hotspot and at many additional sites distributed throughout the entire NAc, and in several limbic or striatal structures beyond (with or without also enhancing "liking"; Gosnell et al., 1986; Ragnauth et al., 2000a; Zhang and Kelley, 2000; Peciña and Berridge, 2005; Woolley et al., 2006; Katsuura and Taha, 2010; Zheng et al., 2010; Mena et al., 2011; Smith et al., 2011; DiFeliceantonio et al., 2012; Mahler and Berridge, 2012; Peciña and Berridge, 2013).

In contrast to $\mathrm{mu}(\mu)$ stimulation, delta $(\delta)$ or kappa $(\kappa)$ stimulation in NAc has mixed or negative effects on food intake. For delta stimulation, several studies reported increases in consumption (Majeed et al., 1986; Bakshi and Kelley, 1993; Zhang and Kelley, 1997; Ragnauth et al., 2000b), whereas other studies reported no change (Katsuura and Taha, 2010). For kappa stimulation in NAc, most studies report no change in intake, (Bakshi and Kelley, 1993; Zhang and Kelley, 1997) although a few early systemic administration studies reported increased intake (Coo- 
per et al., 1985; Jackson and Cooper, 1985), and dynorphin/ $\kappa$ stimulation at most sites in the brain is generally associated with aversive effects (Bals-Kubik et al., 1993; Land et al., 2008; Knoll and Carlezon, 2010; Wee and Koob, 2010).

Here we aimed to better identify and map mu, delta or kappa stimulation effects in NAc medial shell, and to compare potential localizations of function for sensory pleasure versus motivation to eat, as well as the inducement of a conditioned place preference.

\section{Materials and Methods}

Subjects. Male Sprague-Dawley rats, weighing 300-450 g at surgery (total, $n=84$; behavioral taste reactivity and intake groups, $n=21$; behavioral conditioned place preference test groups, $n=39$; dedicated Fos plume radius groups, $n=24$ ) were housed in pairs at $\sim 21^{\circ} \mathrm{C}$ on a reverse $12 \mathrm{~h}$ light/dark cycle. All rats had ad libitum access to both food and water in their home cage. All experimental procedures were approved by the University Committee on the Use and Care of Animals at the University of Michigan.

Surgery. Rats were anesthetized with ketamine hydrochloride $(80 \mathrm{mg} /$ $\mathrm{kg}$, i.p.) and xylazine (5 mg/kg, i.p.), pretreated with atropine $(0.05 \mathrm{mg} /$ $\mathrm{kg}$, i.p.) to prevent respiratory distress, and placed in a stereotaxic apparatus (David Kopf Instruments), with the incisor bar set at $5.0 \mathrm{~mm}$ above intra-aural zero to avoid cannula penetration of lateral ventricles. Rats received bilateral NAc implantation of permanent microinjection guide cannulae (14 mm, 23 gauge, stainless steel) individually aimed at sites staggered throughout the rostrocaudal extent of medial shell. Sites were located between +3.1 and $+2.7 \mathrm{~mm}$ anterior from bregma (AP), bilateral $\pm 0.9 \mathrm{~mm}$ mediolateral (ML), and between -5.7 and $-6.2 \mathrm{~mm}$ dorsoventral (DV). Site coordinates were staggered across individuals so that targets for the group as a whole filled the entire dorsal two-thirds of NAc medial shell, but for a given rat, coordinates were bilaterally symmetrical and as nearly identical as possible in placement on both sides. Microinjection guide cannulae were anchored to the skull using surgical screws and dental acrylic, and stainless steel obturators (28 gauge) were inserted to avoid occlusion except for during behavioral tests.

For rats in the taste reactivity testing group, bilateral oral cannulae were additionally implanted in the same surgery to permit oral infusions of sucrose solutions [polyethylene (PE)-100 tubing]. Oral cannulae entered the mouth in the upper cheek pouch lateral to the first maxillary molar, ascended beneath the zygomatic arch, and exited the skin at the dorsal head cap (Grill and Norgren, 1978). Oral cannulae did not disrupt normal eating. After surgery, each rat received subcutaneous injections of chloramphenicol sodium succinate $(60 \mathrm{mg} / \mathrm{kg})$ to prevent infection and carpofen $(5 \mathrm{mg} / \mathrm{kg})$ for pain relief. Rats received carpofen again $24 \mathrm{~h}$ later and were allowed to recover for 1 week before any behavioral testing occurred.

Drugs and NAc microinjections. Rats were gently cradled by hand in the experimenter's lap during NAc microinjections. PE-20 polyethylene tubing was connected to stainless steel microinjection cannulae (16 mm, 29 gauge) extending $2 \mathrm{~mm}$ beyond the guide cannulae to reach NAc targets. On test days, drug or vehicle solutions were brought to room temperature $\left(\sim 21^{\circ} \mathrm{C}\right)$, and inspected to confirm the absence of precipitation before microinjection. Drugs were prepared at the beginning of each test series, and then either frozen [artificial CSF (ACSF), DAMGO (mu), DPDPE (delta)] or kept refrigerated [U50488H (kappa)] across consecutive test days. All drugs were dissolved in a vehicle of ACSF and microinjected over a $1 \mathrm{~min}$ period at a volume of $0.2 \mu \mathrm{l}$ per side at a speed of 0.2 $\mu \mathrm{l} / \mathrm{min}$ by syringe pump. Injectors were left in place for $1 \mathrm{~min}$ following microinjection to allow drug diffusion, after which obturators were replaced, and rats were immediately placed in the testing chamber. Microinjection solutions contained one of the following: (1) DAMGO, a selective $\mu$ receptor agonist at a dose of $0.05 \mu \mathrm{g} / 0.2 \mu \mathrm{l}$ per side; (2) DPDPE, a selective $\delta$ receptor agonist at a dose of $3.1 \mu \mathrm{g} / 0.2 \mu \mathrm{l}$ per side; (3) $\mathrm{U} 50488 \mathrm{H}$, a selective $\kappa$ receptor agonist at a dose of $0.186 \mu \mathrm{g} / 0.2 \mu \mathrm{l}$ per side, or (4) ACSF vehicle alone in a volume of $0.2 \mu \mathrm{l}$ per side (vehicle control condition). Order of drugs and vehicle were counterbalanced across rats. Rats received only one drug or vehicle microinjection per day.
Drug doses were chosen based on previous studies by Bakshi and Kelley (1993) and by Smith et al., 2011.

Taste reactivity testing. The taste reactivity test (Steiner, 1973; Grill and Norgren, 1978; Steiner et al., 2001) was used to measure affective orofacial reactions of rats to a $1 \mathrm{ml}$ volume of sucrose solution infused into the mouth via oral cannula. Tests occurred during 1 min infusions administered at times when peak pharmacological effects could be expected ( 25 min for vehicle, DAMGO, U50488H, or $15 \mathrm{~min}$ for DPDPE) after drug microinjection (Bakshi and Kelley, 1993). To infuse sucrose solution into the mouth, a syringe containing sucrose in a syringe pump $(1.0 \% ; 0.029$ M; $1 \mathrm{ml}$ per test) was attached via hollow tubing (PE-50 connected to a PE-10 delivery nozzle) to a rat's oral cannula. A $1 \mathrm{ml}$ volume of sucrose was infused evenly over a period of $1 \mathrm{~min}$ duration. Orofacial taste reactivity responses were video-recorded via close-up lens and an angled mirror placed underneath the transparent floor for subsequent slowmotion video analysis.

Taste reactivity video scoring. Hedonic, aversive, and neutral taste reactivity patters were scored off-line in slow motion (1/30 s frame-by-frame to $1 / 10$ th actual speed). Hedonic responses were classified as rhythmic midline tongue protrusions, lateral tongue protrusions, and paw licks (Berridge, 2000). Aversive responses were classified as gapes, head shakes, face washes, forelimb flails, and chin rubs. Neutral responses were classified as passive dripping of solution out of the mouth, ordinary grooming, and rhythmic mouth movements. A time-bin scoring procedure was used to ensure that taste reactivity components of different relative frequencies still contribute equally to final affective hedonic/ aversive totals, and that frequent components such as rhythmic tongue protrusions do not swamp rare but equally informative components, such as lateral tongue protrusions (Berridge, 2000). Specifically, rhythmic mouth movements, passive dripping, and paw licking reactions, which occur in long bouts, were scored in $5 \mathrm{~s}$ time bins (e.g., $5 \mathrm{~s}$ continuous paw licking behavior equals one bout occurrence). Rhythmic midline tongue protrusions and chin rubs, which occur in shorter bouts, were scored in $2 \mathrm{~s}$ time bins. Lateral tongue protrusions, gapes, forelimb flails, and head shakes, which typically occur as discrete events, were scored as single occurrences each time they occurred (e.g., one gape equals one occurrence). Individual totals were calculated for hedonic and aversive categories. A hedonic reaction total was quantified as the sum of scores for lateral tongue protrusion, rhythmic tongue protrusion, and paw lick scores. An aversive reaction total was quantified as the sum of gape, head shake, face wash, forelimb flail, and chin rub scores.

Food intake testing. Spontaneous eating behavior was videorecorded and voluntary food consumption measured in a $1 \mathrm{~h}$ freeintake test that began $1 \mathrm{~min}$ after the taste reactivity test on each microinjection day. Rats were habituated to the food-intake testing chamber for three daily $1 \mathrm{~h}$ sessions before the first microinjection day. Each food intake chamber $(23 \times 20 \times 45 \mathrm{~cm})$ contained $1 \mathrm{~cm}$ depth of corncob bedding, and piles of two foods: palatable chocolates (M\&Ms, $\sim 20 \mathrm{~g}$ ) and standard chow pellets (Purina, $\sim 20 \mathrm{~g}$ ); a water bottle was also always available. Amounts of M\&Ms and chow were weighed before each test and again after the test to calculate amount eaten (chamber was inspected for spillage, and incorporated into amount remaining). All behavior in the chamber was also videorecorded during the $60 \mathrm{~min}$ test, and scored later offline for video analysis by a researcher blind to the drug microinjection condition. Videos were scored for eating behavior (duration in seconds), water drinking behavior (in seconds), grooming behavior (in seconds), and for number of bouts of food sniffs, food carrying (grasping and transport of food by 2 or more steps), cage crosses, and rears (each counted separately).

Conditioned place preference test. Conditioned place preference/avoidance was trained and tested using a three-compartment apparatus ( Tzschentke, 1998; Bardo and Bevins, 2000; Reynolds and Berridge, 2002). Two large side chambers $(28 \times 21 \times 21 \mathrm{~cm})$ surrounded a smaller central compartment $(12 \times 21 \times 21 \mathrm{~cm})$. To allow distinctive sensory cues, one side compartment had an overhead light, black-colored walls, a wire grid floor $(\sim 1 \mathrm{~cm}$ spacing), and scent of soap, whereas the other side compartment had no extra lighting, white walls, a wire mesh floor $(\sim 2 \mathrm{~mm}$ spacing), and scent of $70 \%$ ethanol. 
To first assess any pre-existing preference, rats were pretested by being placed in the center compartment and allowed to freely explore all three chambers for $30 \mathrm{~m}$ while behavior was video-recorded. Preference was calculated by the ratio of cumulative time spent in each side compartment. Whichever compartment an individual rat spent more time in was designated its originally preferred compartment. Opioid agonist microinjections were paired against each rat's original preference (biased procedure), so that DAMGO $(0.05 \mathrm{mg} / 0.2 \mu \mathrm{l}$ per side $), \mathrm{U} 50488 \mathrm{H}(0.186$ $\mathrm{mg} / 0.2 \mu \mathrm{l}$ per side), or DPDPE $(3.1 \mathrm{mg} / 0.2 \mu \mathrm{l}$ per side) microinjections were paired with a rat's unpreferred compartment, and vehicle microinjections were paired with the originally preferred compartment (Tzschentke, 1998; Guo et al., 2008; Wang et al., 2012). Each rat received only one type of opioid agonist, which was paired twice with the same chamber (and vehicle paired twice with the other chamber) in counterbalanced order. Between-group comparisons were made to compare strength of conditioned preferences across the three types of opioid agonist.

On the preference test day (sixth day), rats did not receive any microinjection, and instead were placed directly into the central compartment and allowed to freely explore the entire apparatus for $30 \mathrm{~min}$. Animal behavior during test sessions was videotaped and subsequently scored for cumulative time (seconds) spent in each compartment location. A rat was scored as being inside a particular compartment whenever its head and both forelimbs were within the boundary.

Histology and Fos-like protein immunohistochemistry. Following behavioral testing, rats were deeply anesthetized with an overdose of sodium pentobarbital. Rats in which Fos plumes were measured were perfused and brains treated as described previously (Reynolds and Berridge, 2008; Richard and Berridge, 2011). Fos plumes surrounding microinjection tips were assessed in rats that had been behaviorally tested in taste reactivity and food intake $(n=10)$, and additionally in a separate dedicated Fos group $(n=14)$ that was included to detect the maximal spread of neuronal impact after a single drug microinjection (Richard and Berridge, 2011). In the behavioral group, Fos was assessed after a final (sixth) drug or vehicle microinjection. A dedicated group was also used for Fos because previous results suggested that repetition of up to six serial microinjections during behavioral tests can lead to gradual plume shrinkage by the seventh microinjection, possibly due to gliosis or necrosis around the microinjection tip (Richard and Berridge, 2011). If used alone, shrunken plumes could give rise to overly precise estimates of localization of function in brain maps (due to underestimation of the spread of drug impact). In the dedicated group, which could be expected to have maximum drug spread, a single drug or vehicle microinjection in NAc medial shell was administered under conditions identical to the first day of testing for behavioral rats. Rats were then anesthetized and transcardially perfused $90 \mathrm{~min}$ after their final or sole bilateral microinjection of vehicle $(n=4)$, DAMGO $(n=6)$, U50488H $(n=6)$, or 80 min after their final or sole bilateral microinjection of DPDPE $(n=6)$. Rats with no surgery were also included in a "normal" group $(n=2)$ to assess counts in naive brains. Brain slices were processed for Fos-like immunoreactivity using normal donkey serum, goat anti-c-fos (Santa Cruz Biotechnology), and donkey anti-goat AlexaFluor 488 (Invitrogen). Sections were mounted, air-dried, and coverslipped with Prolong Gold antifade reagent (Invitrogen). Zones where the local expression of fluorescent Fos was elevated in neurons surrounding microinjection sites ("Fos plumes") were assessed via microscope as described previously (Reynolds and Berridge, 2008). Behaviorally tested rats had brains removed and fixed in $10 \%$ paraformaldehyde for $1-2 \mathrm{~d}$ and in $25 \%$ sucrose solution $(0.1 \mathrm{M} \mathrm{NaPb})$ for $3 \mathrm{~d}$ for assessment of microinjection site locations. Brains were sliced at $60 \mu \mathrm{m}$ on a freezing microtome, mounted, airdried, and stained with cresyl violet for verification of microinjection sites. Bilateral microinjection sites for each rat were placed on coronal slices from a rat brain atlas (Paxinos and Watson, 2007), which were used to extrapolate the position of each site on a sagittal map of medial shell.

Mapping behavioral effects of NAc shell microinjections in the sagittal plane allows for the presentation of all sites on the same map of the entire rostrocaudal and dorsoventral extents of NAc medial shell. Functional effects on hedonic and motivated behaviors were mapped using colorcoding to express the intensity changes in affective and motivated behav- iors for individual behaviorally tested rats. Map symbols were sized to match the maximal diameter of Fos plumes measure as described below. For statistical comparison of rostral versus caudal behavioral effects, NAc sites were classified as being in rostral half of shell if located more anterior than $+1.5 \mathrm{~mm}$ ahead of bregma (between +1.5 to +2.4 ), and as in caudal half of shell if located posterior to +1.5 (i.e., between +0.4 to +1.5 bregma).

Regions for statistical analysis. Anatomical regions of interest in medial shell were defined a priori for statistical comparisons. For each behavioral effect, first, rostral versus caudal halves of medial shell were contrasted. This was followed by a finer-grained contrast of dorsal versus ventral quadrants within each half, to separately compare all four quadrants (e.g., rostrodorsal, rostroventral, caudodorsal, caudoventral quadrants). Nonparametric comparisons were made using Friedman's two-way ANOVA or Kruskal-Wallis ANOVA, followed by appropriate Wilcoxon or Mann-Whitney U tests to make paired comparisons.

\section{Results}

\section{Overview}

Overall, each of the three opioid agonists produced enhancements of $200-400 \%$ for positive orofacial reactions elicited by the hedonic impact of sucrose taste infusions when microinjections were made at NAc sites within the rostrodorsal hotspot of medial shell. But none of the opioid agonists enhanced hedonic reactions at any other medial shell sites that were outside the hotspot (e.g., anywhere in caudal shell; see Figs. 2, 4). When microinjection sites were located within the rostrodorsal quadrant of medial shell, the number of positive hedonic orofacial reactions elicited by the taste of sucrose was doubled to quadrupled by microinjections of mu, delta, or even kappa opioid agonists (DAMGO, DPDPE, or U50488H) compared with withinsubject control levels measured after vehicle microinjections in the same rats (Friedman's two-way ANOVA, $X^{2}=12.573, p=$ $0.006)$. No change was statistically detectable for sites in the ventral half of the rostral shell (i.e., rostroventral quadrant; Friedman's two-way ANOVA, $\left.X^{2}=5.57, p=0.134\right)$. In contrast, when microinjection sites were located more posteriorly in the caudal half of NAc medial shell, each of the three agonists suppressed hedonic reactions to sucrose, cutting levels to approximately one-half of vehicle control levels. The hedonic suppression sites in posterior medial shell were anatomically clustered together sufficiently to reveal a caudal "hedonic coldspot" for reducing positive hedonic impact (Friedman's two-way ANOVA, $\left.X^{2}=10.675, p=0.014\right)$.

Conditioned place preference results confirmed that rostrodorsal hotspot sites induced positive reward effects for both mu and kappa agonists (Kruskal-Wallis Test, $X^{2}=16.599, p=$ 0.0001 ), and a similar trend toward a positive rostrodorsal cluster for the $\delta$ agonist (see Fig. 3 ). Sites in the caudal half of medial shell tended to produce a trend toward place avoidance for kappa stimulation, and no consistent place preference effects for mu or delta stimulation.

Finally, opioid stimulations had varied effects on food intake depending on agonist and location, described below $\left(X^{2}=\right.$ $11.796, p=0.008)$.

\section{Fos plume measures: anatomical spread of local drug impact} Measurements of Fos plume sizes indicated first, that repetition of several serial microinjections for behavioral induced shrinkage in the diameter of final Fos plume produced by a drug in the same rat (i.e., a rat's sixth drug microinjection) compared with a first microinjection diameter for that drug in naive rats. For all three opioid agonists, the spread of impact shrunk by $15-75 \%$ in rats that had been previously behavior- 
ally tested, compared with the diameter of plumes induced by the same drug in the dedicated Fos groups, which received only a single microinjection (Fig. 1; $\operatorname{DAMGO}(\mathrm{mu})=33 \%$ shrinkage, $F_{(1,585)}=$ 8.251, $p=0.004$; DPDPE (delta) $=75 \%$ shrinkage, $F_{(1,781)}=120.437, p=0.0004$; $\mathrm{U} 50488 \mathrm{H}(\mathrm{kappa})=15 \%, F_{(1,821)}=7.877$, $p=0.005)$. Shrinkage induced by serial repetition confirmed our supposition that a dedicated Fos group provides more accurate measures of the maximum spread of drug impact, induced by each opioid agonist at the doses and volumes used here, than measuring finalmicroinjection plumes in a previously tested behavioral group. For this reason, all plume sizes described below and used for mapping symbols come from the dedicated Fos groups that were histologically assessed after receiving a single microinjection of their drug or vehicle, and which had the maximum Fos plume diameters.

The functional spread of each opioid agonist microinjection had a radius between 0.15 and $0.2 \mathrm{~mm}$, and a total local volume between 0.014 and $0.034 \mathrm{~mm}^{3}$, as assessed by Fos plumes (Fig. 1). Fos expression was elevated by opioid agonist microinjections within those zones compared with expression levels after vehicle microinjections, or compared with similar sites in normal control brains. Microinjections of the mu agonist DAMGO generated Fos plumes with a total radius of $0.15 \mathrm{~mm}$ ( $0.014 \mathrm{~mm}^{3}$ volume), defined as an elevation $>150 \%$ over normal tissue in the number of neurons expressing Fos protein at points surrounding the microinjector tip $\left(\mathrm{F}_{(4,2776)}=28.193, p=\right.$ $0.0001)$. These contained a smaller central plume with a radius of $0.08 \mathrm{~mm}(0.002$ $\mathrm{mm}^{3}$ volume), defined as $>150 \%$ elevation over vehicle microinjection levels at corresponding points. Vehicle microinjections and cannula implants evoke modest Fos elevations on their own, and therefore a higher drug-induced elevation is required to exceed $150 \%$ of vehiclecontrol levels than is required to exceed $150 \%$ of normal control levels measured in unoperated tissue. For that reason, the inner intense zone of $>150 \%$ vehicle elevation in Fos is smaller than the outer zone of $>150 \%$ elevation over normal spontaneous levels of Fos expression. Delta agonist DPDPE microinjections produced $>150 \%$ normal radius of $0.20 \mathrm{~mm}\left(0.034 \mathrm{~mm}^{3}\right.$ volume $)$, and again a slightly smaller radius of $0.15 \mathrm{~mm}$ compared with vehicle control levels. Kappa agonist U50488H microinjections produced a radius of $0.15 \mathrm{~mm}\left(0.014 \mathrm{~mm}^{3}\right.$ volume $)>150 \%$ elevation over normal tissue, and a slightly smaller radius of $0.13 \mathrm{~mm}$ compared with control vehicle plumes. The averaged diameters
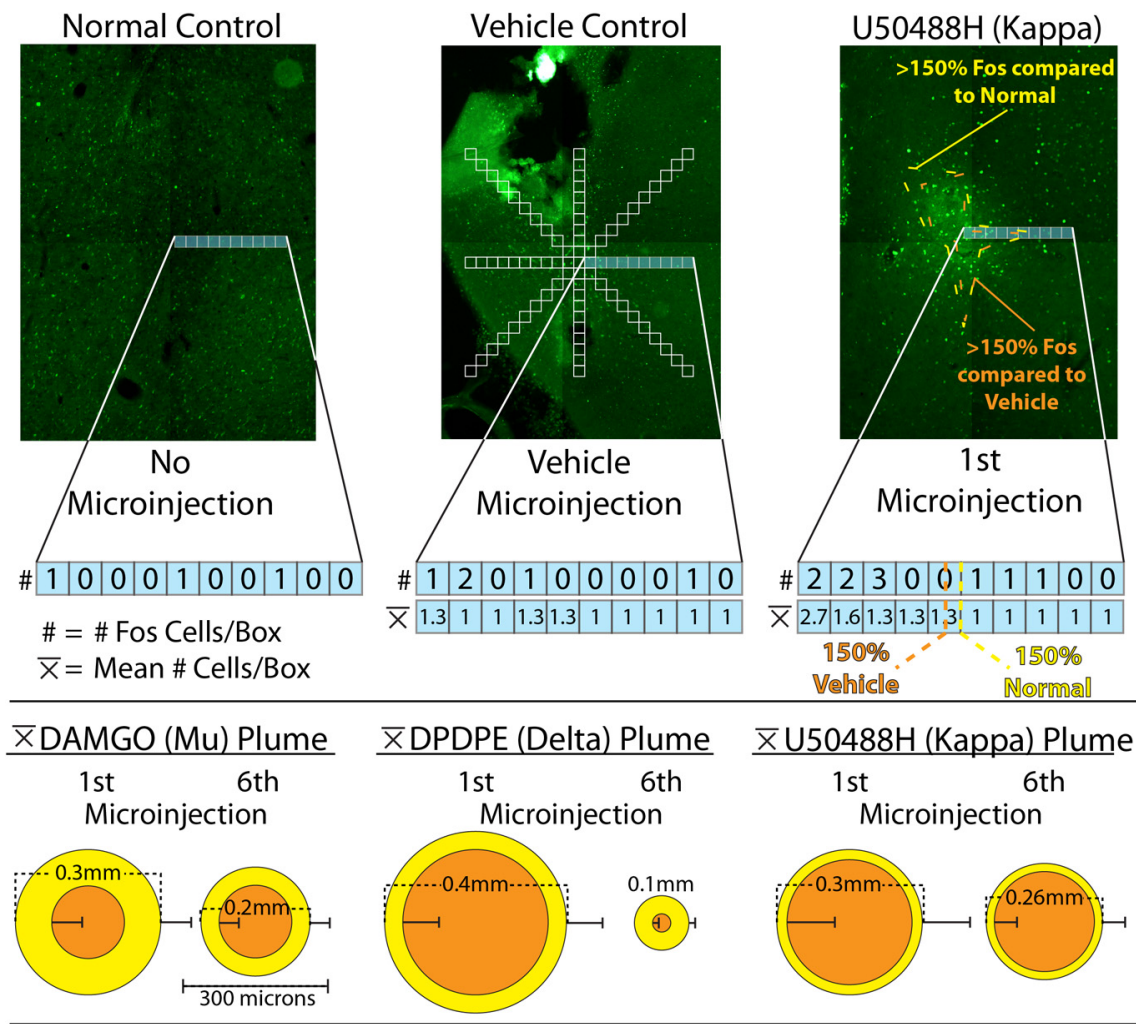

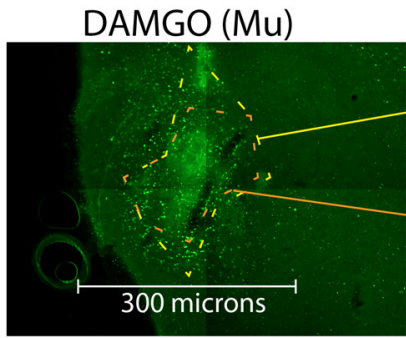

$1 \mathrm{st}$

Microinjection

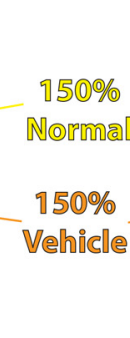

$150 \%$
Noนnล
$150 \%$
Vehic|

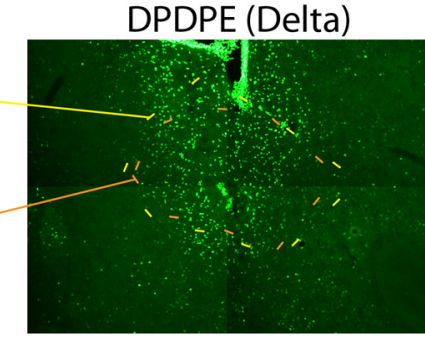

$1 s t$
Microinjection

Figure 1. Fos plume maps for drug microinjections. Local Fos plumes reflect impact spread of a microinjected drug. Photomicrographs (top) show Fos expression in NAc shell of a normal (unoperated) control brain, a control brain that received a vehicle microinjection, and a brain that received a microinjection of U50488 (kappa $\kappa$ ). Each photo also depicts a sample bar showing Fos-expressing neuron counts at points along a radial axis emanating from center of microinjection (or equivalent bar for normal control brain). Numbers reflect the number of neurons in a box that expressed Fos. For microinjections, the average count for the corresponding box in the entire vehicle-microinjection group $(n=4)$ or U50488H $(n=6)$ group is also shown below. Such counts were used to compute elevations of drug-induced Fos compared with normal brains or vehicle brains for the corresponding location. The kappa plume shows the outer limits of where U50488H stimulated Fos expression $>150 \%$ above vehicle microinjection levels (orange dashed line), and slightly larger region where Fos was stimulated $>150 \%$ at least above normal control levels (yellow dashed line). Equivalent plumes are shown in photomicrographs at bottom for microinjections of DAMGO $(n=6 ; \mathrm{mu}$ $(\mu)$ agonist) and of DPDPE $(n=6$; delta $(\delta)$ agonist). The center row show illustrates the magnitude of shrinkage due to serial repetition, from maximal plumes measured after first-time microinjections in the dedicated Fos groups (shown in photomicrographs) to the sixth microinjection in rats that were tested 5 times behaviorally before a final Fos microinjection. Fos-positive labeled cells were individually counted in $50 \times 50 \mu \mathrm{m}$ squares along radial arms extending from the center of the microinjection site at $10 \times$ magnification. Such shrinkage implies that dedicated Fos groups may provide more accurate measures of maximal plume diameter than groups previously tested for behavioral effects.

of Fos plumes measured for each agonist were used to set its symbol size for maximal impact spread in functional maps (see Figs. 2-4). These measurements were also used therefore to calculate the volume of rostrodorsal hedonic hotspot and caudal hedonic coldspot derived from the functional maps. All other information in function maps shows behavioral effects of drug microinjections on taste reactivity and food intake at depicted sites (symbol colors depict effect intensities; symbol placements 
depict site locations; bar graphs depict behavioral intensities at AP or DV stereotactic levels).

\section{Rostrodorsal localization of hedonic enhancement in medial shell}

At sites in the rostrodorsal quadrant of medial shell, the number of positive hedonic reactions elicited by the taste of sucrose was more than doubled by DAMGO, DPDPE, or U50488H microinjections (Fig. 2; Friedman's two-way ANOVA, $X^{2}=12.573, p=$ 0.006 ; described separately below). Hedonic enhancements produced within the rostrodorsal quadrant were always greater than produced by the same drugs in any of the other three quadrants of medial shell $\left(X^{2}=24.723, p=0.0001\right)$, which all failed to produce any increase over vehicle levels in the number of positive reactions elicited by sucrose $\left(X^{2}=5.57, p=0.134\right)$.

\section{Mu localization in rostral hotspot}

$\mathrm{Mu}$ receptor stimulation by DAMGO microinjections at sites within the rostrodorsal quadrant nearly quadrupled the number of hedonic reactions elicited by sucrose taste (median $=400 \%$, $Z=-3.059, p=0.002)$. The rostrodorsal localization of $\mathrm{mu}$ enhancement was significantly greater compared with the other three quadrants of medial shell $(Z=-3.114, p=0.001)$.

\section{Delta localization in rostral hotspot}

Delta stimulation by DPDPE microinjections in the rostrodorsal quadrant nearly tripled hedonic reactions elicited by the taste of sucrose compared with vehicle levels in the same rats (median $=$ 292\%; $Z=-2.346, p=0.019$ ). Again, the rostrodorsal delta enhancement was significantly higher compared with the other three quadrants of medial shell $(Z=-2.926, p=0.002)$.

Kappa localization in rostral hotspot

Perhaps most surprisingly, even kappa stimulation by U50488H microinjections inside the rostrodorsal quadrant more than doubled positive hedonic reactions to sucrose (median $=225 \%, Z=$ $-2.703, p=0.007$ ). Kappa enhancement in the rostrodorsal quadrant was significantly higher compared with the other three quadrants $(Z=-2.744, p=0.004)$. Although this is the first report to our knowledge that kappa opioid stimulation can enhance sensory pleasure impact in any brain region, we emphasize that kappa hedonic enhancement was observed only for sites within the rostrodorsal hotspot.

Thus, within the rostrodorsal quadrant, all three opioid agonists produced increases that were valence-specific to positive hedonic orofacial reactions to sucrose (e.g., rhythmic and lateral tongue protrusions, and paw licks). The number of aversive reactions (e.g., gapes) remained near zero and never was altered, even by opioid agonist microinjections in the rostrodorsal quadrant (Friedman's two-way ANOVA, $X^{2}=5.567, p=0.135$ ). Finally, although the magnitude of hedonic enhancement nominally varied from twofold for kappa to threefold for delta and up to fourfold for mu within the rostrodorsal hotspot, those magnitudes of increase did not differ statistically from each other across agonists (Friedman's two-way ANOVA, $X^{2}=3.455, p=0.178$ ), suggesting that within the hotspot boundaries all three types of opioid stimulation produce hedonic enhancements of comparable intensity.

\section{Defining anatomical boundaries for opioid hedonic enhancement and suppression}

To more precisely map its anatomical boundaries, we operationally defined the hotspot as a spatial region containing contiguous plume-diameter sites which produced hedonic reaction eleva- tions of at least $150 \%$ (compared with vehicle control levels in the same rat). Defined that way, the rostrodorsal hotspot extended dorsally to the top of NAc shell and was anatomically bounded by lateral septum and the lateral ventricles. Ventrally, the hotspot extended just past the dorsoventral midpoint in medial shell, and touched the islands of Calleja. Medially, the hotspot extended to the medial edge of shell, and laterally extended to the edge of the NAc core. Relative to stereotaxic placements, the entire rostrocaudal extent of the hotspot ran approximately from $+2.20 \mathrm{~mm}$ anterior to bregma (none of our sites hit further rostral portions of NAc) posteriorly to $+1.5 \mathrm{~mm}$ bregma, or almost to the AP midpoint of the medial shell. The ventral boundary of the hotspot in our map was not as clear as we would have wished because our microinjection sites the most ventral strip of the medial shell. The sparseness of ventral sites makes it more difficult to have full confidence in the exact placement of the ventral boundary for the hedonic hotspot. However, there appeared to be a trend in the rostral bar graphs of Figure 2, suggesting a decline in the intensity of DAMGO hedonic enhancement as hotspot sites moved ventrally in shell, potentially matching the ventral boundary originally outlined for the mu hotspot (Peciña and Berridge, 2005). The centers of microinjection sites within the hotspot ranged within $\sim 1.1 \mathrm{~mm} \mathrm{DV} \times 0.5 \mathrm{~mm} \mathrm{ML} \times 0.8 \mathrm{~mm} \mathrm{AP}(\mathrm{DV}:-6.2$ to $-7.3 \mathrm{~mm}$; ML: \pm 0.4 to $\pm 0.9 \mathrm{~mm}$; AP: +2.4 to $+1.6 \mathrm{~mm}$ ). Given that DAMGO produced Fos plumes with radii extending to 0.15 $\mathrm{mm}$ at its maximum extent (defined as $>150 \%$ elevation over normal unoperated NAc tissue), that implies that the range of Fos elevation produced by those microinjection sites would extend along a DV axis of $1.4 \mathrm{~mm}$, ML of $0.8 \mathrm{~mm}$, and AP of $1.1 \mathrm{~mm}$.

Regarding cubic volume, the coordinates above were used to calculate a total volume of $\sim 1.2 \mathrm{~mm}^{3}$ for the mu hotspot where $>150 \%$ enhancements in hedonic reactions were produced. Using a smaller Fos plume based on Fos elevation $>150 \%$ over Fos levels produced by vehicle microinjections (for the same points surrounding the microinjection tip) as a more conservative estimate of DAMGO spread of impact, the mu hotspot volume would decline slightly to $\sim 0.8 \mathrm{~mm}^{3}$. These values of 1.2 and 0.8 $\mathrm{mm}^{3}$ essentially bracket the original $1.0 \mathrm{~mm}^{3}$ estimate of the volume of the NAc mu hotspot (Peciña and Berridge, 2005). For DPDPE enhancements, the delta hotspot volume was estimated between 1.2 and $1.62 \mathrm{~mm}^{3}$. For U50488H enhancements, the kappa hotspot volume was estimated between 1.2 and 1.1 $\mathrm{mm}^{3}$. Altogether, these values indicate that the entire opioid NAc hedonic hotspot has a total volume of $\sim 1 \mathrm{~mm}^{3}$ or slightly larger. By comparison, the volume of the entire medial shell is $\sim 3 \mathrm{~mm}^{3}$ and the volume of the entire NAc is $\sim 10 \mathrm{~mm}^{3}$ (shell and core combined).

\section{Posterior coldspot for hedonic suppression}

In contrast to rostral enhancements above, a suppressive coldspot was observed for all three opioid agonists in the caudal half of medial shell. In the posterior half of medial shell microinjections of DAMGO, DPDPE, or U50488H generally reduced positive hedonic reactions to sucrose taste to approximately one-half of vehicle control levels (Friedman's two-way ANOVA, $X^{2}=$ $10.675, p=0.014)$. A rostral versus caudal comparison for hedonic effects in medial shell shows that mu, delta, or kappa stimulation all had opposite effects in anterior versus posterior halves $\left(X^{2}=37.899, p=0.0001\right)$.

However, the magnitude of suppression produced at caudal sites differed somewhat across the three drugs $\left(X^{2}=6.867, p=\right.$ 0.032). 


\section{Hedonic Reactions Food Intake}

\section{A Mu (DAMGO) Hedonic Hotspot and Diffuse Food Intake Enhancement \% Vehicle}

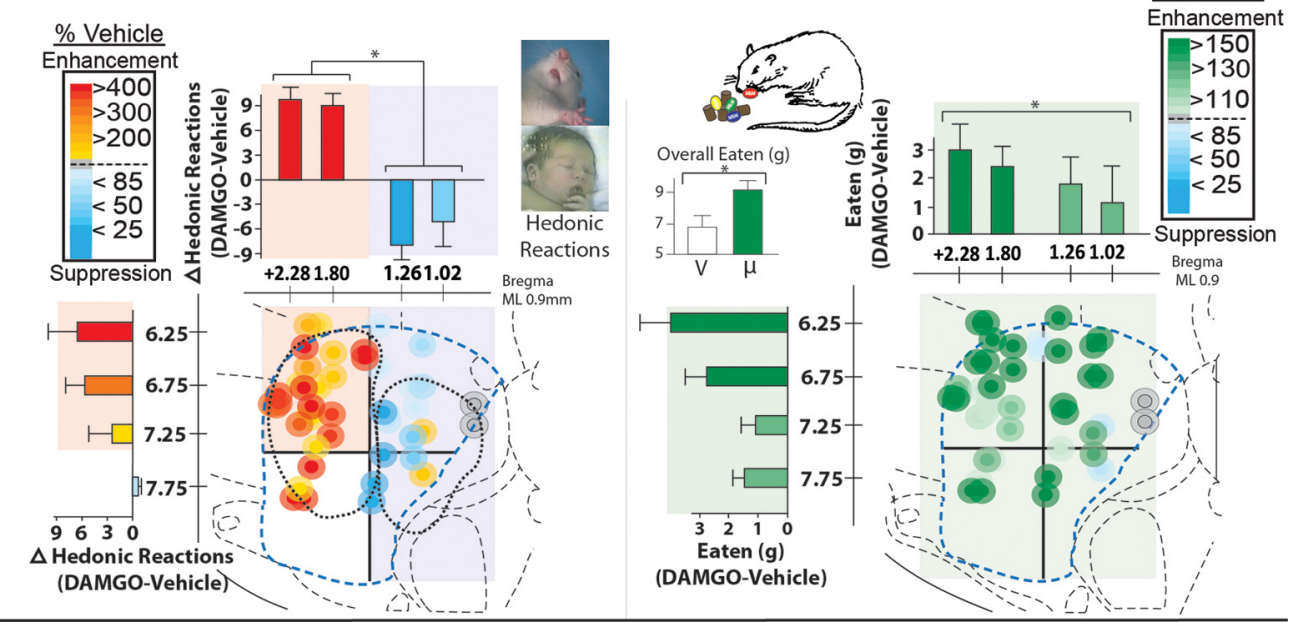

\section{B Delta (DPDPE) Hedonic and Food Intake Hotspot Enhancement}

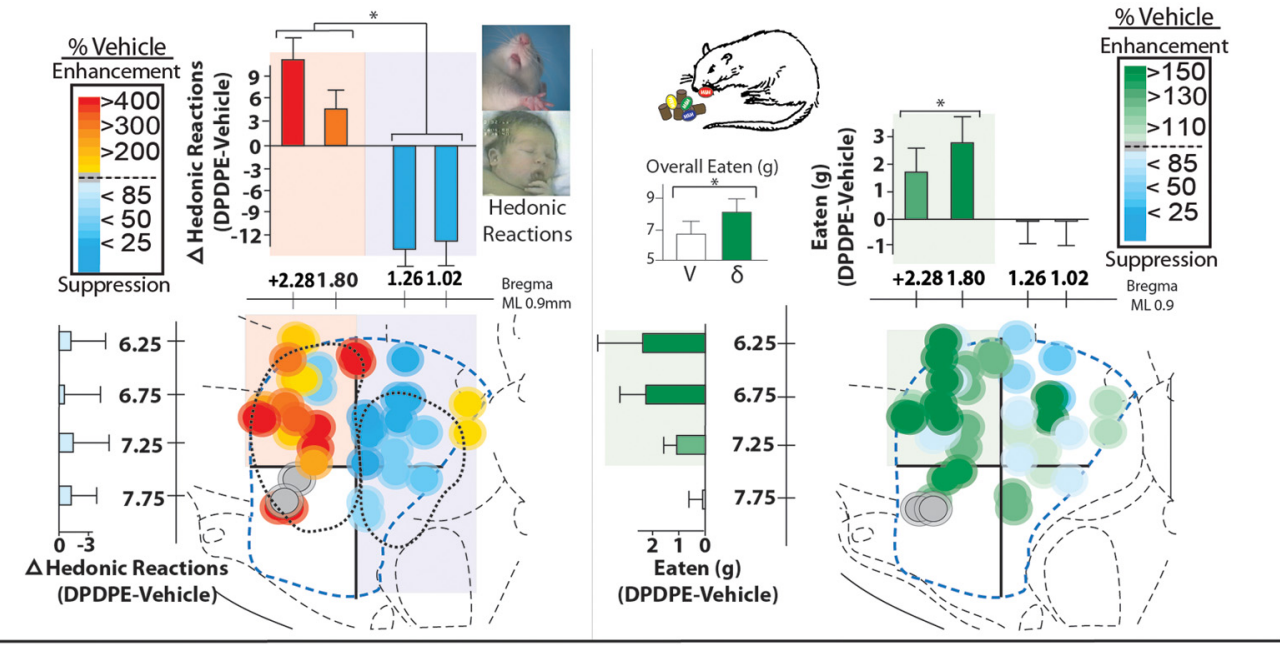

\section{Kappa (U50488H) Hedonic Hotspot and Mixed Food Intake Effects}

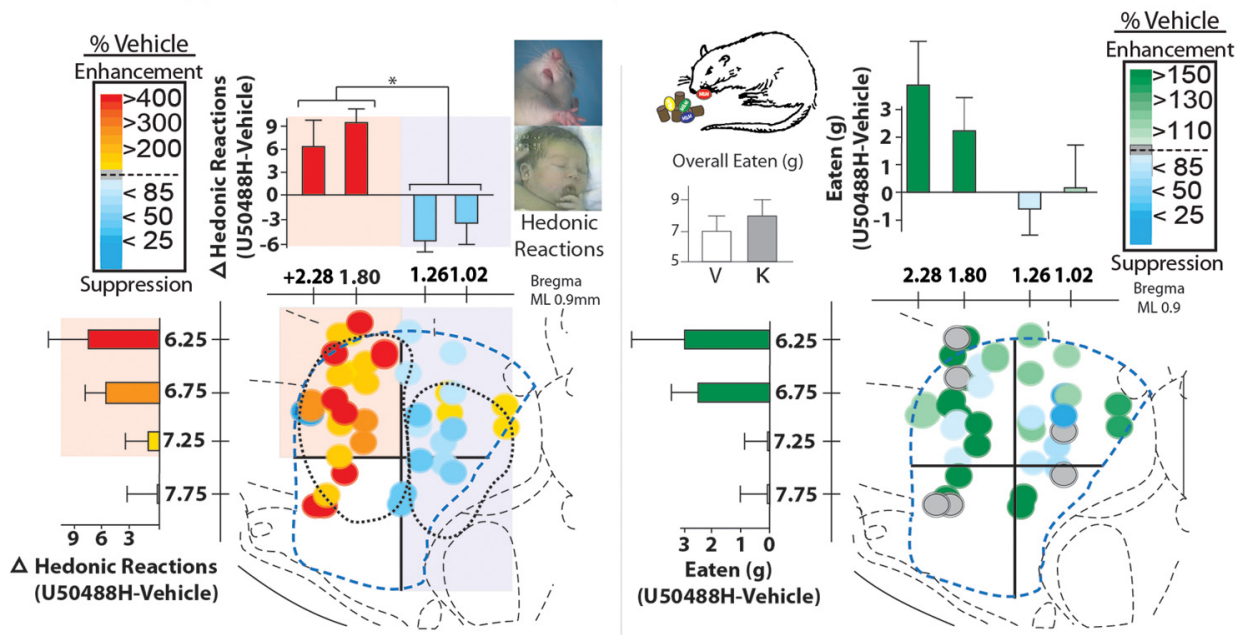

Figure 2. Causation maps for localization of "liking" versus "wanting" enhancements. Sagittal maps of NAc medial shell show changes that each type of opioid agonist microinjection induced in hedonic reactions to sucrose taste (left column) and in food intake (right column) within the same individual rat (compared with taste reactions and food intake after vehicle microinjection; $n=21$ ). Rows show mu (DAMG0; $\boldsymbol{A}$ ), delta (DPDPE; $\boldsymbol{B}$ ), or kappa (U50488H; $\boldsymbol{C}$ effects. Behavioral changes are displayed as percentage changes from vehicle control levels, and both bilateral microinjection sites are plotted on the single sagittal map. Bars show mean intensity of behavioral changes produced at each stereotaxic level (anterior-posterior and dorsal-ventral levels). Colors also show intensity of behavioral changes (percentage change from within-subject vehicle control levels) induced at each site. Enhancements of "liking" in the left column are depicted in yellow, orange, and red, whereas suppression of "liking" reactions is depicted by blue. In the right column, eating enhancement is displayed by green, and suppression of eating by blue. (Figure legend continues.) 
Delta caudal coldspot

DPDPE in the caudal half of medial shell suppressed positive reactions to only $40 \%$ of control vehicle levels $(Z=-2.380$, $p=0.017)$. This posterior suppression was again opposite from anterior enhancements caused by DPDPE microinjections $(Z=-3.514, p=0.0001)$.

Kappa caudal hotspot

Kappa stimulation suppressed hedonic reactions to sucrose in caudomedial shell by $\sim 50 \%$ compared with vehicle controls $(Z=-2.035, p=0.042)$. This kappa suppressive hedonic effect seems compatible with previous reports on kappa function in reward. For example, Land et al. (2008) reported that kappa receptor activation in NAc and basolateral amygdala encodes the dysphoric component of a stressful event. Similarly, Wee and Koob (2010) suggested that kappa activation may be responsible for the aversive or dysphoric component of drug withdrawal. Our results suggest that kappa suppression of positive hedonic impact may be localized in medial shell to primarily the caudal half, similarly to the localization of hedonic suppression effects for mu and delta stimulation found here.

Mu caudal coldspot

In the caudal half of medial shell, mu stimulation only nonsignificantly suppressed "liking" reactions elicited by sucrose to $66 \%$ of control levels $(Z=-1.863, p=0.063)$. Still, this trend toward posterior suppression was significantly different from the anterior enhancements caused by microinjections of the same DAMGO drug in the rostrodorsal shell $(Z=-3.626, p=$ $0.0001)$.

\section{Anatomical borders and volume of caudal suppressive coldspot}

The caudal coldspot penetrated both the dorsal and ventral quadrants of the caudal half of medial shell. Like the hotspot, the dorsal border appeared to touch the lateral septum and the lateral ventricles. The medial border changes based on the anteroposterior plane, beginning with the island of Calleja $(\mathrm{AP}+1.56)$ at the rostral edge of the caudal coldspot, then lateral septum (AP +0.96 ), and finally rostral ventral pallidum at the most caudal edge of the coldspot (AP +0.72). The ventral border appeared to extend to rostral ventral pallidum (raising the possibility that the NAc coldspot may be continuous with another opioid hedonic coldspot previously mapped within the rostral half of the ventral pallidum itself; Smith and Berridge, 2005). The lateral border touched predominantly the NAc core at most points, but posteriorly transitions to bed nucleus of the stria terminalis at is most caudal points.

Mapping the coldspot borders with the same technique as for the hotspot, the caudal hedonic coldspot (sites producing $30 \%$ or greater suppression of hedonic reactions) extended from AP +1.5 to $+0.8 \mathrm{~mm}, \mathrm{ML} \pm 0.4$ to $\pm 0.9 \mathrm{~mm}$, and DV -6.3 to -7.9 $\mathrm{mm}$ (caudal medial shell shrinks in the dorsoventral plane as it becomes posterior). For the mu coldspot, the trapezoidal volume was $\sim 1.3$ to $\sim 0.9 \mathrm{~mm}^{3}$. For the delta hedonic coldspot, the corresponding volume was between $\sim 1.8$ and $\sim 1.3 \mathrm{~mm}^{3}$. For the

\section{$\leftarrow$}

(Figure legend continued.) In both columns, gray indicates no change from vehicle control level. The size of sagittal map symbols is scaled to measured Fos plume diameters for each drug. The dashed circle in rostral accumbens shows the anatomical outline of the mu hotspot originally described by Peciña and Berridge (2005) for comparison to present data, and the caudal dashed circle represents their original mu coldspot. kappa coldspot, the volume of was between $\sim 1.3$ and $\sim 1.2 \mathrm{~mm}^{3}$. Altogether, these overlapping results suggest that the anatomically localized hedonic coldspot in caudal accumbens slightly exceeds $1 \mathrm{~mm}^{3}$ in volume, and is therefore comparable in size to the rostrodorsal hedonic hotspot.

\section{Food intake and eating behavior}

In $1 \mathrm{~h}$ free-intake tests conducted immediately after taste reactivity tests with sweet M\&M chocolates and ordinary chow available, opioid stimulations significantly altered the total amount eaten in ways that depended on the particular agonist and precise site (Fig. 2; Friedman's two-way ANOVA, $X^{2}=11.796$, $p=$ 0.008 ). In all cases, consumption was almost exclusively of palatable M\&Ms.

The three agonists produced very different NAc anatomical patterns within medial shell of effects on food intake. For mu stimulation, DAMGO microinjections at all sites throughout the entire medial shell homogeneously enhanced the consumption of food by nearly $140 \%$ above vehicle $(Z=-3.250, p=0.001)$. Consumption of palatable chocolate M\&Ms rose from $\sim 6.5 \mathrm{~g}$ after vehicle microinjection to $8.0 \mathrm{~g}$ after DAMGO $(Z=-2.698, p=0.007)$. The mu increase in consumption was comparable in magnitude at all sites throughout the entire medial shell, and did not differ between rostral and caudal halves $(Z=-0.362, p=0.750)$. This broad anatomical distribution for mu-stimulated sites of hyperphagia is consistent with earlier reports that DAMGO throughout entire NAc, as well as in other structures, including central amygdala and parts of neostriatum, can increase consumption of palatable food (Ragnauth et al., 2000a; Zhang and Kelley, 2000; Peciña and Berridge, 2005; Mena et al., 2011; DiFeliceantonio et al., 2012).

For delta stimulation of intake, DPDPE microinjections also enhanced eating in medial shell, specifically enhancing consumption of palatable M\&M chocolates $(Z=-2.129, p=0.033)$. However, an anatomical analysis revealed that sites for the observed delta increase in eating were not broadly distributed across medial shell, but rather were confined within the rostrodorsal hotspot $(Z=-2.866, p=$ 0.004 , median $=125 \%$ compared with vehicle). By comparison, in the posterior half of medial shell, delta stimulation had no detectable effect on intake (total eaten: $Z=-0.070, p=0.944$ ), and the elevation of eating behavior in the rostrodorsal hotspot quadrant was larger than produced in the other three quadrants $(Z=-2.034, p=$ 0.044 ). Thus, delta stimulation enhanced eating, but only within the rostrodorsal hotspot.

By contrast, kappa receptor stimulation did not produce a clear enhancement of intake at any anatomical site in medial shell $(Z=$ $-1.064, p=0.287$, median $=110 \%$ ), although there was a nonsignificant trend toward $>150 \%$ increase in several sites concentrated in the rostrodorsal hotspot $(Z=-1.824, p=0.68)$. An inspection of kappa stimulation in rostral hotspot versus caudal coldspot effects on eating showed no difference between anterior versus posterior halves of medial shell $(Z=-0.926, p=0.384)$. However, we did observe a strikingly large individual variance in kappa-stimulated eating, which was nearly three times as large as vehicle variance and twice as large as any other opioid agonist type (vehicle variance, 8.799; DAMGO variance, 12.7; DPDPE, 10.882; U50488H, 23.473). That is, some rats intensely increased their consumption after U50488H microinjection ( $>10 \mathrm{~g}$ above vehicle), but other rats were either not affected at all or even ate $\sim 30 \%$ less compared with after vehicle ( $\sim 1.5 \mathrm{~g}$ less). The lack of a consistent kappa change in intake seems consistent with previous reports of no overall change in food consumption after kappa stimulation in NAc medial shell (Bakshi and Kelley, 1993; Zhang and Kelley, 1997). 


\section{Conditioned place preference}

Conditioned place preference results indicated that the rostral NAc hotspot more effectively supported establishment of a positive conditioned place preference for all three types of opioid stimulation than other regions of medial shell (Friedman two-way ANOVA, $X^{2}=9.80, p=0.002$ ). Within the rostral half of medial shell, microinjection sites in the dorsal two-thirds induced a conditioned place preference of $216 \%$ for mu stimulation $(Z=-2.201$, $p=0.28)$, a $168 \%$ preference for kappa stimulation $(Z=-2.197, p=0.028)$, and a $139 \%$ trend toward preference for delta stimulation, although the last did not reach statistical significance. However, the strength of delta conditioned preference was not statistically lower than either mu or kappa preference $(Z=-1.387, p=$ $0.183)$, consistent with the possibility of a delta preference. ( $Z=1.69, p=0.091)$. Inside the rostrodorsal hotspot, mu and kappa stimulations produced comparable magnitudes of positive place preference of $\sim 170$ to $\sim 215 \%$, and did not differ from each other $(Z=-1.359, p=0.181)$.

Anatomical comparison of sites across medial shell indicated that only inside the rostrodorsal hotspot did kappa or mu microinjections produce positive place preferences, whereas the same drug microinjections in other regions of medial shell outside the hotspot failed to produce any significant preference (e.g., no preference induced in the entire caudal half of medial shell; Fig. 3; U5088H, $Z=-2.714, p=0.005$; DAMGO, $Z=-2.429, p=$ $0.014)$. That is, even for mu stimulation, DAMGO microinjections in the posterior half of medial shell failed to establish a significant preference $(Z=-0.507, p=0.612)$. These results appear similar to a previous report of failure to produce a conditioned place preference by DAMGO microinjections into NAc core, lateral hypothalamus, or medial prefrontal cortex (BalsKubik et al., 1993). However, as a caveat, our data were inadequate to draw a strong conclusion about mu stimulation in the most ventral one-third of medial shell, leaving some uncertainty for mu stimulation in that subregion. For $\kappa$ sites outside the hotspot, we found a trend toward establishing negative place avoidance of $33 \%(Z=-1.782, p=0.075)$. A conditioned place avoidance for most of shell would be similar to reports that kappa stimulation in the adjacent core of NAc produced a conditioned place avoidance (Bals-Kubik et al., 1993).

\section{Discussion}

Our results confirm that the rostrodorsal quadrant of medial shell in NAc contains a specialized opioid hedonic hotspot, $\sim 1$ $\mathrm{mm}^{3}$ in volume, where $\mathrm{mu}(\mu)$ stimulation generates $200-400 \%$ enhancements of "liking" reactions to sweetness. We report that delta $(\delta)$ and kappa $(\kappa)$ stimulations also amplify hedonic impact similarly within the hotspot. The functional uniqueness of the hotspot in rostrodorsal shell contrasts to lack of capacity to generate comparable hedonic enhancement observed for at least all sites in the remaining two-thirds of medial shell mapped here (caudal and rostroventral), and potentially in the remaining $90 \%$

\section{Opioid Hotspot Induces Condition Place Preferences}

\section{$\mathrm{Mu} \quad$ Delta}

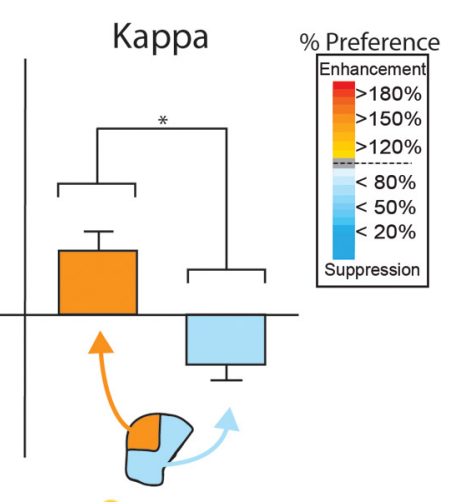

(1)
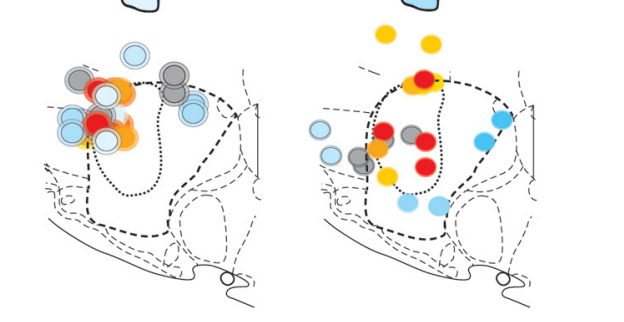

Figure 3. Causation maps for conditioned place preference. Sagittal maps and overall effects for establishment of conditioned place (rostroventral $1 / 3$ of medial shell plus entire caudal half; right bar of each pair). Sagittal maps are similar to Figure 2. Red and orange indicates establishment of a positive place preference, and blue indicates a negative place avoidance. The dotted outline in the rostrodorsal portion of large slices indicate the original mu hotspot as originally defined by Peciña and Berridge (2005).

of entire NAc (shell and core combined). Our results also mapped a separate suppressive coldspot in the caudal half of shell, $\sim 1.3 \mathrm{~mm}^{3}$ in volume, where each opioid stimulation oppositely reduced sucrose positive "liking" reactions to approximately onehalf normal levels. Confirming a unique reward-related role for the rostrodorsal quadrant, we further showed that mu or kappa stimulations produced positive conditioned place preference at sites specifically within the hotspot (and a positive trend for delta), but not at outside sites in other subregions. Finally, we identified several anatomical differences between NAc opioid controls of "liking" versus "wanting" to eat. These results highlight NAc anatomical heterogeneity and localization of opioid reward-related functions within medial shell.

Neurobiological sources for endogenous opioid ligands in NAc include dynorphin (kappa ligand) released from medium spiny neurons (MSNs) that express D1 receptors, and enkephalin (delta and mu ligand) from D2-expressing MSNs (Ghazarossian et al., 1980; Raynor et al., 1994). Dynorphin and enkephalin are also released by input projections from other structures, including ventral pallidum and lateral hypothalamus (Haber et al., 1985; Peyron et al., 1998; Groenewegen et al., 1999; Baldo et al., 2003). In addition, $\beta$-endorphin (potent mu ligand) may reach NAc medial shell via projections from the arcuate nucleus of hypothalamus (Khachaturian et al., 1984; Raynor et al., 1994).

Postsynaptic receptors for mu, delta, and kappa in NAc are reported on dendrites of most MSNs (Gracy et al., 1997; Svingos et al., 1999a,b, 2001b). Mu receptors likely predominate on D1 MSNs (e.g., direct path), but can also occur on D2 MSNs (indirect path) as well as on acetylcholine interneurons (Svingos et al., 1996, 2001a). In contrast, delta and kappa receptors may predominate on D2 MSNs (Svingos et al., 1996, 1998, 1999b), and 
also exist on presynaptic terminals of glutamate and dopamine projections into NAc (Svingos et al., 1999a,b; Hjelmstad and Fields, 2001). All three opioid receptors are G-protein-coupled receptors that can recruit ERK $1 / 2$ inside neurons in a Rasdependent manner via the G $\beta \gamma$ subunit, though through different intracellular pathways (Belcheva et al., 1998). For example, mu activation recruits ERK via $\mathrm{PKC} \varepsilon$, whereas kappa stimulation recruits PLC3 (Belcheva et al., 2005). These neurobiological distributions may be relevant to the functional pattern of effects described here.

Potential neurobiological basis for the rostrodorsal hotspot Several distinctive neurobiological features exist for the hotspot's rostrodorsal quadrant of medial shell that may be relevant to its unique hedonic function (Fig. 4; Thompson and Swanson, 2010; Zahm et al., 2013). For example, Thompson and Swanson (2010) anatomically traced a unique closed-loop corticolimbic-thalamocortical circuit through the NAc hotspot in the rostrodorsal quadrant of medial shell, potentially in parallel to other segregated loops involving different shell subregions. They reported that the rostrodorsal quadrant received corticolimbic inputs from one particular subregion of prefrontal infralimbic cortex (homologous to Brodmanns area 25 in humans), and sent unique output projections to distinct subregions of lateral hypothalamus and ventral pallidum. From there, pallidothalamic and hypothalamo-thalamic projections were relayed via thalamus to the original infralimbic subregion, thereby completing a segregated corticolimbic-thalamocortical loop (Thompson and Swanson, 2010).

Separately, Zahm et al. (2013) reported additional distinguishing features of the rostral subregion containing the medial shell hotspot, suggesting that the rostral shell constitutes a distinct anatomical NAc-septal transition zone related to lateral septum. By contrast, they suggested that the caudal half of medial shell constitutes a different transition zone related to structures of extended amygdala. Further neurochemical and cellular specializations may additionally distinguish the rostrodorsal quadrant or rostral half from other subregions of medial shell (Hanlon et al., 2004; Britt and McGehee, 2008; Park et al., 2010). Such features may eventually help explain the rostrodorsal hotspot's unique opioid ability to robustly generate hedonic enhancements.

\section{Comparison to neuroimaging measures}

Human neuroimaging studies also implicate NAc circuitry and opioid activation in both reward and pain modulation (Zubieta et al., 2005; Zubieta and Stohler, 2009; Leknes et al., 2011; Wanigasekera et al., 2012). However, it is difficult to compare such neuroimaging results to our localization of a NAc hedonic hotspot until future refinements in anatomical resolution permit better contrast of the rostrodorsal quadrant to other subregions of medial shell. Even then, a potentially important difference may remain; our opioid hotspot localization applies particularly to opioid causation (i.e., magnification of sucrose "liking"), whereas neuroimaging (and even anatomically precise electrophysiological and neurochemical measures of neural activation) assess regional coding that occurs in correlation with hedonic events. It remains for now an open question whether the same localization rules will apply to opioid causation and to coding of the same hedonic functions (especially because some coding sites may reflect hedonic-guided causation of other learning, cognition, etc. functions distinct from "liking"; Berridge and Kringelbach, 2013).

\section{Paradoxical kappa hedonic enhancement in rostral hotspot}

Perhaps our most surprising finding was that kappa stimulation produced any positive enhancements at all for "liking" and conditioned place preference; even though only at sites limited to the rostrodorsal hotspot. No other NAc study to our knowledge has previously reported positive reward effects for kappa stimulation. Instead, kappa stimulation is commonly viewed to cause mostly negative effects, such as conditioned place avoidance, at least at sites in NAc core, ventral tegmentum, or prefrontal cortex (Mucha and Herz, 1985; Bals-Kubik et al., 1989; Bals-Kubik et al., 1993; Kim et al., 2004; McLaughlin et al., 2006). In accordance with such negative-valence dominance, we found kappa stimulation produced place avoidance effects at most sites in NAc medial shell: the entire caudal half of shell (which also produced suppression of "liking" reactions to sucrose), as well as rostral sites that were ventral to the hotspot, or that were so far anterior as to be outside the NAc hotspot. We suggest that anatomical heterogeneity gates the valence of kappa effects in NAc, inducing positive reward within the rostrodorsal shell hotspot but mostly negative effects elsewhere.

\section{Controlling motivation for food: "wanting"}

Opioid enhancements of "wanting" to eat more food, expressed as increases in eating behavior and consumption, differed somewhat from "liking" enhancements. Delta stimulation of intake ( $>140 \%)$ by DPDPE microinjection was anatomically limited to the rostrodorsal hotspot. At all other sites in medial shell, delta stimulation failed to stimulate intake at all. It seems plausible that previous positive reports of delta stimulation inducing eating increases in NAc may have predominantly targeted the rostrodorsal zone of shell (Majeed et al., 1986; Zhang and Kelley, 1997; Ragnauth et al., 2000a; Richard et al., 2013).

By comparison, mu and kappa stimulations produced strong anatomical dissociations between "wanting" versus "liking" effects. For mu stimulation of eating (>140\%), "wanting" substrates anatomically extended additionally beyond the hotspot and throughout the entire medial shell (remaining strong even in caudal shell). This is consistent with previous reports that DAMGO stimulates eating at many NAc shell and core sites, as well as at sites of neostriatum, amygdala, etc. (Majeed et al., 1986; Gosnell and Majchrzak, 1989; Zhang and Kelley, 1997, 2000; Echo et al., 2002; Peciña and Berridge, 2005; Mahler and Berridge, 2009; DiFeliceantonio et al., 2012). It is also consistent with anatomically widespread mu enhancements for other aspects of "wanting", as for example reflected in measures of learned seeking for rewards (Zhang et al., 2003; Hanlon et al., 2004; Peciña and Berridge, 2013).

Finally, kappa stimulation failed to consistently increase in food intake at any shell sites. Kappa stimulation doubled intake in some individuals but reduced intake by half in other individuals, producing variability with no discernible anatomical pattern. Our failure to find kappa-induced increases in intake seems consistent with previous reports of no change.

\section{Clinical applications}

Deficits of positive hedonic impact (anhedonia or dysphoria) may be involved in major depression or in bipolar disorder (Treadway and Zald, 2011; Der-Avakian and Markou, 2012), 


\section{One Unique Opioid Hotspot}

A

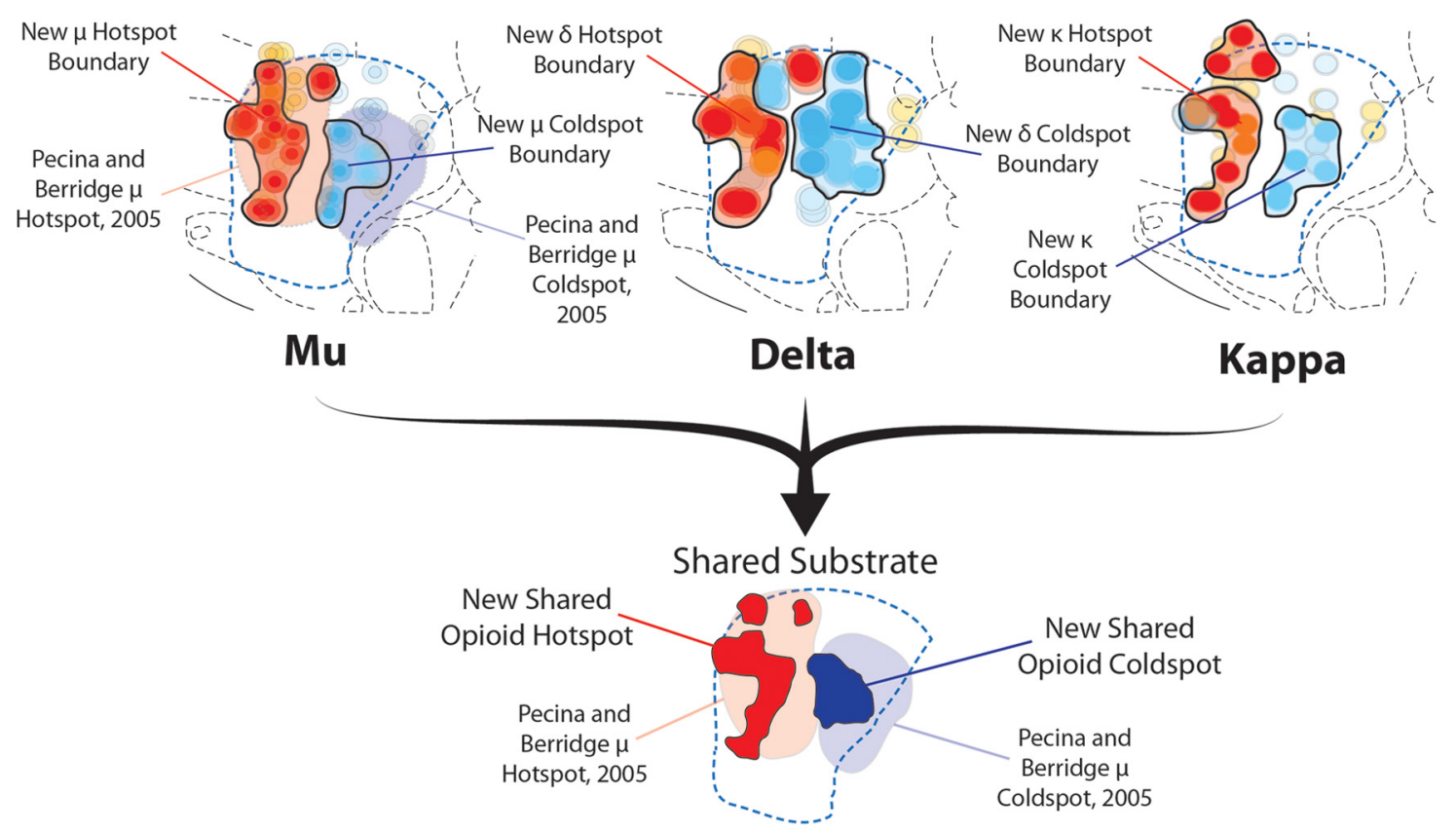

B Hotspot Anatomical Connections

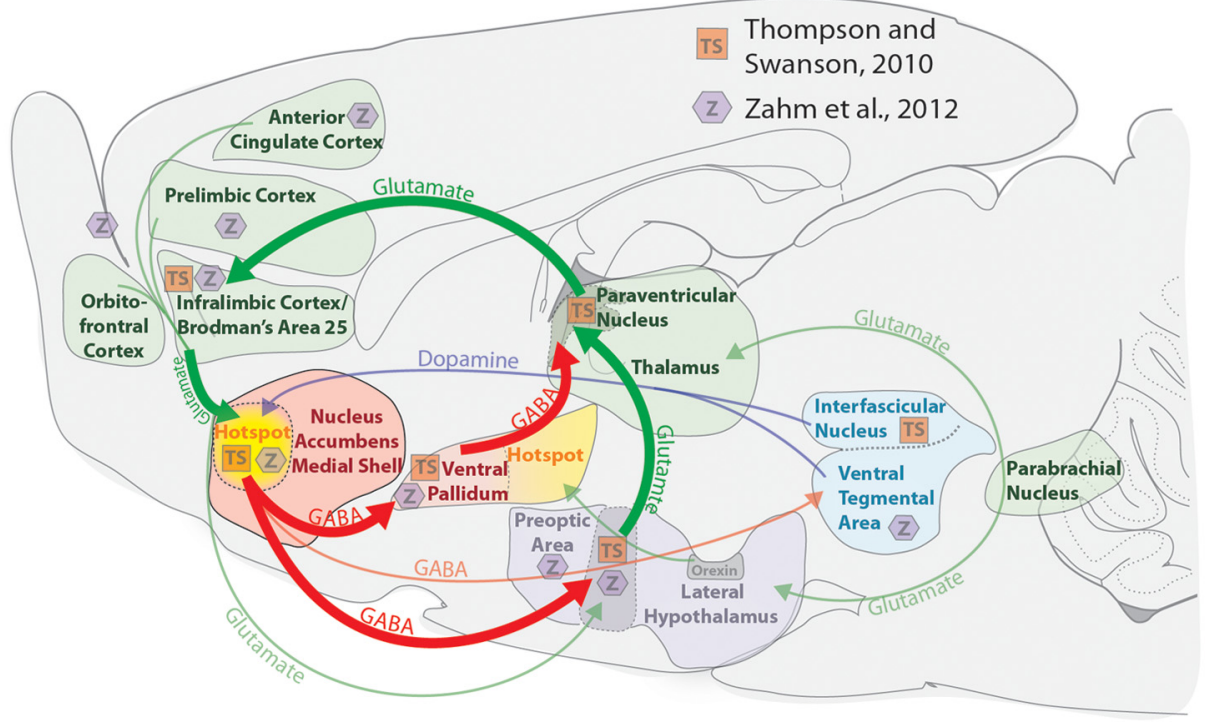

Figure 4. Summary maps for NAcopioid hotspots and coldspots in medial shell and relevant anatomical circuitry. $\boldsymbol{A}$, Sagittal summary maps of NAcmedial shell for mu, delta, or kappa hedonic enhancements (rostral hotspots) and suppressions (caudal coldspots) of sucrose "liking" observed here. Hotspot outlines are defined anatomically by contiguous groups of microinjection sites (sized to match Fos plumes) that caused $>250 \%$ enhancements of positive orofacial hedonic reactions elicited by sucrose taste, and coldspot boundaries are defined by contiguous sites that caused suppressions to below one-half of control vehicle levels for sucrose "liking" reactions. The mu panel also shows for comparison the original hotspot and coldspot boundaries (Peciña and Berridge, 2005). The shared substrate map below is a subtraction map showing sites that produced equivalent hotspot enhancements for all three opioid stimulations, or equivalent coldspot suppressions for all three agonist microinjections. $\boldsymbol{B}$, Anatomical circuitry features relevant to the hotspot of rostrodorsal medial shell, as described in text (based on Thompson and Swanson (2010) and on Zahm et al., (2013); TS symbol in orange boxes depicts unique features of rostrocaudal quadrant of medial shell described by Thompson and Swanson; Z symbol in purple hexagons depicts features of rostral half of medial shell described by Zahm et al.). Hedonic hotspots are shown in yellow, GABAergic projections in red, glutamatergic projections in green, and dopaminergic projections in blue. Modified from (Richard et al., 2013).

whereas excessive motivational "wanting" to consume rewards characterizes compulsive consumption disorders, such as binge eating and addiction (Avena et al., 2008; Shin et al., 2010; Spijker et al., 2010; Rubin, 2012). Opioid reward circuitry in NAc is implicated in both types of dysfunction (Bruchas et al., 2010; Giuliano et al., 2012; Katsuura and Taha, 2014; Kupchik et al.,
2014), suggesting that aberrant localizable mechanisms within NAc shell may be relevant to understanding such disorders. Better understanding of NAc heterogeneity, and localization of opioid functions in generating intense "liking" and "wanting", may prove useful in unraveling such psychopathologies, and eventually aid in creating more effective treatments. 


\section{References}

Avena NM, Rada P, Hoebel BG (2008) Evidence for sugar addiction: behavioral and neurochemical effects of intermittent, excessive sugar intake. Neurosci Biobehav Rev 32:20-39. CrossRef Medline

Bakshi VP, Kelley AE (1993) Feeding induced by opioid stimulation of the ventral striatum: role of opiate receptor subtypes. J Pharmacol Exp Ther 265:1253-1260. Medline

Baldo BA, Daniel RA, Berridge CW, Kelley AE (2003) Overlapping distributions of orexin/hypocretin- and dopamine-beta-hydroxylase immunoreactive fibers in rat brain regions mediating arousal, motivation, and stress. J Comp Neurol 464:220-237. CrossRef Medline

Bals-Kubik R, Herz A, Shippenberg TS (1989) Evidence that the aversive effects of opioid antagonists and kappa-agonists are centrally mediated. Psychopharmacology (Berl) 98:203-206. CrossRef Medline

Bals-Kubik R, Ableitner A, Herz A, Shippenberg TS (1993) Neuroanatomical sites mediating the motivational effects of opioids as mapped by the conditioned place preference paradigm in rats. J Pharmacol Exp Ther 264:489-495. Medline

Bardo MT, Bevins RA (2000) Conditioned place preference: what does it add to our preclinical understanding of drug reward? Psychopharmacology (Berl) 153:31-43. CrossRef Medline

Belcheva MM, Vogel Z, Ignatova E, Avidor-Reiss T, Zippel R, Levy R, Young EC, Barg J, Coscia CJ (1998) Opioid modulation of extracellular signalregulated protein kinase activity is ras-dependent and involves Gbetagamma subunits. J Neurochem 70:635-645. CrossRef Medline

Belcheva MM, Clark AL, Haas PD, Serna JS, Hahn JW, Kiss A, Coscia CJ (2005) Mu and kappa opioid receptors activate ERK/MAPK via different protein kinase $\mathrm{C}$ isoforms and secondary messengers in astrocytes. J Biol Chem 280:27662-27669. CrossRef Medline

Berner LA, Bocarsly ME, Hoebel BG, Avena NM (2011) Pharmacological interventions for binge eating: lessons from animal models, current treatments, and future directions. Curr Pharm Des 17:1180-1187. CrossRef Medline

Berridge KC (2000) Measuring hedonic impact in animals and infants: microstructure of affective taste reactivity patterns. Neurosci Biobehav Rev 24:173-198. CrossRef Medline

Berridge KC, Kringelbach ML (2013) Neuroscience of affect: brain mechanisms of pleasure and displeasure. Curr Opin Neurobiol 23:294-303. CrossRef Medline

Berridge KC, Ho CY, Richard JM, DiFeliceantonio AG (2010) The tempted brain eats: pleasure and desire circuits in obesity and eating disorders. Brain Res 1350:43-64. CrossRef Medline

Britt JP, McGehee DS (2008) Presynaptic opioid and nicotinic receptor modulation of dopamine overflow in the nucleus accumbens. J Neurosci 28:1672-1681. CrossRef Medline

Bruchas MR, Land BB, Chavkin C (2010) The dynorphin/kappa opioid system as a modulator of stress-induced and pro-addictive behaviors. Brain Res 1314:44-55. CrossRef Medline

Cooper SJ, Jackson A, Kirkham TC (1985) Endorphins and food intake: kappa opioid receptor agonists and hyperphagia. Pharmacol Biochem Behav 23:889-901. CrossRef Medline

Der-Avakian A, Markou A (2012) The neurobiology of anhedonia and other reward-related deficits. Trends Neurosci 35:68-77. CrossRef Medline

DiFeliceantonio AG, Mabrouk OS, Kennedy RT, Berridge KC (2012) Enkephalin surges in dorsal neostriatum as a signal to eat. Curr Biol 22: 1918-1924. CrossRef Medline

Echo JA, Lamonte N, Ackerman TF, Bodnar RJ (2002) Alterations in food intake elicited by GABA and opioid agonists and antagonists administered into the ventral tegmental area region of rats. Physiol Behav 76:107116. CrossRef Medline

Ghazarossian VE, Chavkin C, Goldstein A (1980) A specific radioimmunoassay for the novel opioid peptide dynorphin. Life Sci 27:75-86. CrossRef Medline

Giuliano C, Robbins TW, Nathan PJ, Bullmore ET, Everitt BJ (2012) Inhibition of opioid transmission at the mu-opioid receptor prevents both food seeking and binge-like eating. Neuropsychopharmacology 37:26432652. CrossRef Medline

Gosnell BA, Majchrzak MJ (1989) Centrally administered opioid peptides stimulate saccharin intake in nondeprived rats. Pharmacol Biochem Behav 33:805-810. CrossRef Medline

Gosnell BA, Levine AS, Morley JE (1986) The stimulation of food intake by selective agonists of mu, kappa and delta opioid receptors. Life Sci 38: 1081-1088. CrossRef Medline
Gracy KN, Svingos AL, Pickel VM (1997) Dual ultrastructural localization of mu-opioid receptors and NMDA-type glutamate receptors in the shell of the rat nucleus accumbens. J Neurosci 17:4839-4848. Medline

Grill HJ, Norgren R (1978) The taste reactivity test: I. Mimetic responses to gustatory stimuli in neurologically normal rats. Brain Res 143:263-279. CrossRef Medline

Groenewegen HJ, Wright CI, Beijer AV, Voorn P (1999) Convergence and segregation of ventral striatal inputs and outputs. Ann N Y Acad Sci 877: 49-63. CrossRef Medline

Grueter BA, Rothwell PE, Malenka RC (2012) Integrating synaptic plasticity and striatal circuit function in addiction. Curr Opin Neurobiol 22:545551. CrossRef Medline

Guo N, Garcia MM, Taylor BK, Zadina JE, Harlan RE (2008) Blockade of micro-opioid receptors in the medial thalamus inhibits acquisition, but not expression, of morphine-induced conditioned place preference. Neuroscience 151:948-954. CrossRef Medline

Haber SN, Groenewegen HJ, Grove EA, Nauta WJ (1985) Efferent connections of the ventral pallidum: evidence of a dual striato pallidofugal pathway. J Comp Neurol 235:322-335. CrossRef Medline

Hanlon EC, Baldo BA, Sadeghian K, Kelley AE (2004) Increases in food intake or food-seeking behavior induced by GABAergic, opioid, or dopaminergic stimulation of the nucleus accumbens: is it hunger? Psychopharmacology (Berl) 172:241-247. CrossRef Medline

Hjelmstad GO, Fields HL (2001) Kappa opioid receptor inhibition of glutamatergic transmission in the nucleus accumbens shell. J Neurophysiol 85:1153-1158. Medline

Ito R, Robbins TW, Everitt BJ (2004) Differential control over cocaineseeking behavior by nucleus accumbens core and shell. Nat Neurosci 7:389-397. CrossRef Medline

Jackson A, Cooper SJ (1985) Effects of kappa opiate agonists on palatable food consumption in non-deprived rats, with and without food preloads. Brain Res Bull 15:391-396. CrossRef Medline

Katsuura Y, Taha SA (2010) Modulation of feeding and locomotion through mu and delta opioid receptor signaling in the nucleus accumbens. Neuropeptides 44:225-232. CrossRef Medline

Katsuura Y, Taha SA (2014) Mu opioid receptor antagonism in the nucleus accumbens shell blocks consumption of a preferred sucrose solution in an anticipatory contrast paradigm. Neuroscience 261:144-152. CrossRef Medline

Khachaturian H, Lewis ME, Haber SN, Akil H, Watson SJ (1984) Proopiomelanocortin peptide immunocytochemistry in rhesus monkey brain. Brain Res Bull 13:785-800. CrossRef Medline

Kim JA, Pollak KA, Hjelmstad GO, Fields HL (2004) A single cocaine exposure enhances both opioid reward and aversion through a ventral tegmental area-dependent mechanism. Proc Natl Acad Sci U S A 101:5664-5669. CrossRef Medline

Knoll AT, Carlezon WA Jr (2010) Dynorphin, stress, and depression. Brain Res 1314:56-73. CrossRef Medline

Koob GF (2000) Neurobiology of addiction: toward the development of new therapies. Ann N Y Acad Sci 909:170-185. CrossRef Medline

Kupchik YM, Scofield MD, Rice KC, Cheng K, Roques BP, Kalivas PW (2014) Cocaine dysregulates opioid gating of GABA neurotransmission in the ventral pallidum. J Neurosci 34:1057-1066. CrossRef Medline

Land BB, Bruchas MR, Lemos JC, Xu M, Melief EJ, Chavkin C (2008) The dysphoric component of stress is encoded by activation of the dynorphin $\kappa$-opioid system. J Neurosci 28:407-414. CrossRef Medline

Leknes S, Lee M, Berna C, Andersson J, Tracey I (2011) Relief as a reward: hedonic and neural responses to safety from pain. PLoS One 6:e17870. CrossRef Medline

Mahler SV, Berridge KC (2009) Which cue to "want?" Central amygdala opioid activation enhances and focuses incentive salience on a prepotent reward cue. J Neurosci 29:6500-6513. CrossRef Medline

Mahler SV, Berridge KC (2012) What and when to "want"? Amygdalabased focusing of incentive salience upon sugar and sex. Psychopharmacology (Berl) 221:407-426. CrossRef Medline

Majeed NH, Przewłocka B, Wedzony K, Przewlocki R (1986) Stimulation of food intake following opioid microinjection into the nucleus accumbens septi in rats. Peptides 7:711-716. CrossRef Medline

McLaughlin JP, Land BB, Li S, Pintar JE, Chavkin C (2006) Prior activation of kappa opioid receptors by U50,488 mimics repeated forced swim stress to potentiate cocaine place preference conditioning. Neuropsychopharmacology 31:787-794. CrossRef Medline

Mena JD, Sadeghian K, Baldo BA (2011) Induction of hyperphagia and car- 
bohydrate intake by $\mu$-opioid receptor stimulation in circumscribed regions of frontal cortex. J Neurosci 31:3249-3260. CrossRef Medline

Michaelides M, Anderson SA, Ananth M, Smirnov D, Thanos PK, Neumaier JF, Wang GJ, Volkow ND, Hurd YL (2013) Whole-brain circuit dissection in free-moving animals reveals cell-specific mesocorticolimbic networks. J Clin Invest 123:5342-5350. CrossRef Medline

Mucha RF, Herz A (1985) Motivational properties of kappa and mu opioid receptor agonists studied with place and taste preference conditioning. Psychopharmacology (Berl) 86:274-280. CrossRef Medline

Nathan PJ, Bullmore ET (2009) From taste hedonics to motivational drive: central $\mu$-opioid receptors and binge-eating behaviour. Int J Neuropsychopharmacol 12:995-1008. CrossRef Medline

Park J, Aragona BJ, Kile BM, Carelli RM, Wightman RM (2010) In vivo voltammetric monitoring of catecholamine release in subterritories of the nucleus accumbens shell. Neuroscience 169:132-142. CrossRef Medline

Paxinos G, Watson C (2007) The rat brain in stereotaxic coordinates. New York: Academic.

Peciña S, Berridge KC (2005) Hedonic hot spot in nucleus accumbens shell: where do $\mu$-opioids cause increased hedonic impact of sweetness? J Neurosci 25:11777-11786. CrossRef Medline

Peciña S, Berridge KC (2013) Dopamine or opioid stimulation of nucleus accumbens similarly amplify cue-triggered "wanting" for reward: entire core and medial shell mapped as substrates for PIT enhancement. Eur J Neurosci 37:1529-1540. CrossRef Medline

Peyron C, Tighe DK, van den Pol AN, de Lecea L, Heller HC, Sutcliffe JG, Kilduff TS (1998) Neurons containing hypocretin (orexin) project to multiple neuronal systems. J Neurosci 18:9996-10015. Medline

Ragnauth A, Moroz M, Bodnar RJ (2000a) Multiple opioid receptors mediate feeding elicited by mu and delta opioid receptor subtype agonists in the nucleus accumbens shell in rats. Brain Res 876:76-87. CrossRef Medline

Ragnauth A, Znamensky V, Moroz M, Bodnar RJ (2000b) Analysis of dopamine receptor antagonism upon feeding elicited by mu and delta opioid agonists in the shell region of the nucleus accumbens. Brain Res 877:6572. CrossRef Medline

Raynor K, Kong H, Chen Y, Yasuda K, Yu L, Bell GI, Reisine T (1994) Pharmacological characterization of the cloned kappa-, delta-, and mu-opioid receptors. Mol Pharmacol 45:330-334. Medline

Resendez SL, Dome M, Gormley G, Franco D, Nevárez N, Hamid AA, Aragona BJ (2013) $\mu$-Opioid receptors within subregions of the striatum mediate pair bond formation through parallel yet distinct reward mechanisms. J Neurosci 33:9140-9149. CrossRef Medline

Reynolds SM, Berridge KC (2002) Positive and negative motivation in nucleus accumbens shell: bivalent rostrocaudal gradients for GABA-elicited eating, taste "liking"/“disliking" reactions, place preference/avoidance, and fear. J Neurosci 22:7308-7320. Medline

Reynolds SM, Berridge KC (2008) Emotional environments retune the valence of appetitive versus fearful functions in nucleus accumbens. Nat Neurosci 11:423-425. CrossRef Medline

Richard JM, Berridge KC (2011) Nucleus accumbens dopamine/glutamate interaction switches modes to generate desire versus dread: $\mathrm{D}(1)$ alone for appetitive eating but $\mathrm{D}(1)$ and $\mathrm{D}(2)$ together for fear. J Neurosci 31 : 12866-12879. CrossRef Medline

Richard JM, Castro DC, DiFeliceantonio AG, Robinson MJ, Berridge KC (2013) Mapping brain circuits of reward and motivation: in the footsteps of Ann Kelley. Neurosci Biobehav Rev 37:1919-1931. CrossRef Medline

Rubin DH (2012) Joy returns last: anhedonia and treatment resistance in depressed adolescents. J Am Acad Child Adolesc Psychiatry 51:353-355. CrossRef Medline

Shin AC, Pistell PJ, Phifer CB, Berthoud HR (2010) Reversible suppression of food reward behavior by chronic mu-opioid receptor antagonism in the nucleus accumbens. Neuroscience 170:580-588. CrossRef Medline

Smith KS, Berridge KC (2005) The ventral pallidum and hedonic reward: neurochemical maps of sucrose "liking" and food intake. J Neurosci 25: 8637-8649. CrossRef Medline

Smith KS, Berridge KC (2007) Opioid limbic circuit for reward: interaction between hedonic hotspots of nucleus accumbens and ventral pallidum. J Neurosci 27:1594-1605. CrossRef Medline

Smith KS, Berridge KC, Aldridge JW (2011) Disentangling pleasure from incentive salience and learning signals in brain reward circuitry. Proc Natl Acad Sci U S A 108:E255-264. CrossRef Medline

Spijker J, de Graaf R, Ten Have M, Nolen WA, Speckens A (2010) Predictors of suicidality in depressive spectrum disorders in the general population: results of the Netherlands mental health survey and incidence study. Soc Psychiatry Psychiatr Epidemiol 45:513-521. CrossRef Medline

Steiner JE (1973) The gustofacial response: observation on normal and anencephalic newborn infants. Symp Oral Sens Percept 4:254-278. Medline

Steiner JE, Glaser D, Hawilo ME, Berridge KC (2001) Comparative expression of hedonic impact: affective reactions to taste by human infants and other primates. Neurosci Biobehav Rev 25:53-74. CrossRef Medline

Svingos AL, Moriwaki A, Wang JB, Uhl GR, Pickel VM (1996) Ultrastructural immunocytochemical localization of mu-opioid receptors in rat nucleus accumbens: extrasynaptic plasmalemmal distribution and association with Leu5-enkephalin. J Neurosci 16:4162-4173. Medline

Svingos AL, Clarke CL, Pickel VM (1998) Cellular sites for activation of delta-opioid receptors in the rat nucleus accumbens shell: relationship with Met5-enkephalin. J Neurosci 18:1923-1933. Medline

Svingos AL, Clarke CL, Pickel VM (1999a) Localization of the $\delta$-opioid receptor and dopamine transporter in the nucleus accumbens shell: implications for opiate and psychostimulant cross-sensitization. Synapse 34:1-10. CrossRef Medline

Svingos AL, Colago EE, Pickel VM (1999b) Cellular sites for dynorphin activation of $\kappa$-opioid receptors in the rat nucleus accumbens shell. J Neurosci 19:18041813. Medline

Svingos AL, Colago EE, Pickel VM (2001a) Vesicular acetylcholine transporter in the rat nucleus accumbens shell: subcellular distribution and association with mu-opioid receptors. Synapse 40:184-192. CrossRef Medline

Svingos AL, Chavkin C, Colago EE, Pickel VM (2001b) Major coexpression of kappa-opioid receptors and the dopamine transporter in nucleus accumbens axonal profiles. Synapse 42:185-192. CrossRef Medline

Thompson RH, Swanson LW (2010) Hypothesis-driven structural connectivity analysis supports network over hierarchical model of brain architecture. Proc Natl Acad Sci U S A 107:15235-15239. CrossRef Medline

Treadway MT, Zald DH (2011) Reconsidering anhedonia in depression: lessons from translational neuroscience. Neurosci Biobehav Rev 35:537555. CrossRef Medline

Tzschentke TM (1998) Measuring reward with the conditioned place preference paradigm: a comprehensive review of drug effects, recent progress and new issues. Prog Neurobiol 56:613-672. CrossRef Medline

Wang J, Wu X, Li C, Wei J, Jiang H, Liu C, Yu C, Carlson S, Hu X, Ma H, Duan W, Ma Y (2012) Effect of morphine on conditioned place preference in rhesus monkeys. Addict Biol 17:539-546. CrossRef Medline

Wanigasekera V, Lee MC, Rogers R, Kong Y, Leknes S, Andersson J, Tracey I (2012) Baseline reward circuitry activity and trait reward responsiveness predict expression of opioid analgesia in healthy subjects. Proc Natl Acad Sci U S A 109:17705-17710. CrossRef Medline

Wee S, Koob GF (2010) The role of the dynorphin-kappa opioid system in the reinforcing effects of drugs of abuse. Psychopharmacology (Berl) 210: 121-135. CrossRef Medline

Woolley JD, Lee BS, Fields HL (2006) Nucleus accumbens opioids regulate flavor-based preferences in food consumption. Neuroscience 143:309 317. CrossRef Medline

Zahm DS, Parsley KP, Schwartz ZM, Cheng AY (2013) On lateral septumlike characteristics of outputs from the accumbal hedonic "hotspot" of Peciña and Berridge with commentary on the transitional nature of basal forebrain "boundaries." J Comp Neurol 521:50-68. CrossRef Medline

Zhang M, Kelley AE (1997) Opiate agonists microinjected into the nucleus accumbens enhance sucrose drinking in rats. Psychopharmacology (Berl) 132:350-360. CrossRef Medline

Zhang M, Kelley AE (2000) Enhanced intake of high-fat food following striatal mu-opioid stimulation: microinjection mapping and fos expression. Neuroscience 99:267-277. CrossRef Medline

Zhang M, Balmadrid C, Kelley AE (2003) Nucleus accumbens opioid, GABaergic, and dopaminergic modulation of palatable food motivation: contrasting effects revealed by a progressive ratio study in the rat. Behav Neurosci 117:202-211. CrossRef Medline

Zheng H, Townsend RL, Shin AC, Patterson LM, Phifer CB, Berthoud HR (2010) High-fat intake induced by mu-opioid activation of the nucleus accumbens is inhibited by Y1R-blockade and MC3/4R- stimulation. Brain Res 1350:131-138. CrossRef Medline

Zubieta JK, Stohler CS (2009) Neurobiological mechanisms of placebo responses. Ann N Y Acad Sci 1156:198-210. CrossRef Medline

Zubieta JK, Bueller JA, Jackson LR, Scott DJ, Xu Y, Koeppe RA, Nichols TE, Stohler CS (2005) Placebo effects mediated by endogenous opioid activity on mu-opioid receptors. J Neurosci 25:7754-7762. CrossRef Medline 